\title{
Analysis Of Differences in Attributes of Burnout Syndrome and Coping Strategies in Managers in Terms of Gender
}

\author{
Barbara Nicole ČIGARSKÁ ${ }^{\star}$, Zuzana BIRKNEROVÁ \\ ${ }^{1}$ Ph.D. student, University of Prešov in Prešov, Faculty of Management, Department of Managerial Psychology, \\ Konštantínova 16, 08001 Prešov, Slovakia, Email: barbara.nicole.cigarska@smail.unipo.sk \\ ${ }^{2}$ Associate Professor, University of Prešov in Prešov, Faculty of Management, Department of Managerial Psychology, \\ Konštantínova 16, 08001 Prešov, Slovakia, Email: zuzana.birknerova@unipo.sk \\ * Corresponding Author
}

\begin{abstract}
Received: 09.11.2021 Accepted: 11.12.2021 Published: 01.02.2022 DOI: 10.47750/QAS/23.186.28
\end{abstract}
\begin{abstract}
Burnout syndrome represents the main problem in the physical and mental state of an individual. It represents one of the most studied work-related syndromes in current years. Burnout syndrome is closely related to energy reduction, overtiredness, chronic stress from work that is not well-managed. The study aimed to analyze statistically significant differences between attributes of burnout syndrome and coping strategies in managers in terms of gender. Main attributes or determinants of burnout syndrome are Depersonalization, Emotional Exhaustion, and Personal Accomplishment. The Maslach Burnout Inventory (MBI) and the Brief COPE Inventory (COPE) were included, depending on research purposes. The $\mathrm{MBI}$ consisted of twenty-two questions individually dealing with determinants, and the Brief COPE methodology summarized fourteen coping strategies that help cope with stress. It was used to find out how managers behave in demanding situations and which coping strategies they use. The research was conducted on a representative sample of managers $(N=249)$ by online questionnaire in the Slovak republic. The research assumed the existence of positive differences between the assessment of determinants and coping strategies. The results confirmed the existence of statistically significant gender differences $(p<.001)$ between attributes of burnout syndrome and certain coping strategies in managers in terms of demanding situations. It means that there are differences between managers in dealing with difficult situations and when using coping strategies. Male managers appeared to be depersonalized and emotionally exhausted more often than female managers.
\end{abstract}

Keywords: burnout syndrome, coping strategies, managers, gender differences, a burden

\section{Theoretical background of Burnout syndrome in terms of gender among managers}

Mental illnesses are disturbing and crossover with depression is not easily treated. It is a sign that the individual drained himself and this can be irreversible (Stringer et al., 2015). Burnout is a reaction to persistent work stress and socalled work-related burnout is conceptualized as a threedimensional construct, examined by Maslach Burnout Inventory. The $\mathrm{MBI}$ includes determinants: Emotional Exhaustion, Depersonalization, and Personal Accomplishment (Maslach, Leiter, 2008; Brubaker, Beverly, 2020). Emotional Exhaustion and Depersonalization defined as types of strain are viewed as fundamental mechanisms of burnout (Purvanova, Muros, 2010). Burnout syndrome represents one of the most studied workrelated syndromes in recent decades, particularly within the healthcare sector and sector of services (Heinemann, 2017). In 2018 was burnout syndrome included in the 11th Revision of the International Classification of Diseases and it was described as a syndrome resulting from chronic, unsuccessfully managed work stress that activates cynicism, withdrawal, emotional exhaustion, loss of idealism, feelings of unproductivity, unsuccessfulness, and ineffectiveness (WHO, 2019). Burnedout individuals experience high levels of chronic fatigue, distance themselves emotionally and cognitively from their work activities (Bakker, Costa, 2014). The widespread problem affects dissimilar professions, mostly medical students, doctoral students, lawyers, nurses, athletes, artists, teachers, earlycareer individuals, managers, people in leading positions, businessmen, or individuals who put the greatest effort into passion or work; known as perfectionists (Brubaker, Beverly, 2020; Carter, 2013). Factors such as perfectionism and neuroticism play a substantial role in the development of burnout syndrome since these factors predispose individuals to choose not suitable coping strategies (Swider, Zimmerman, 2010).

Despite increasing evidence on the association between burnout and work-related stress, there exist limited knowledge about the range to which individuals' characteristics such as gender and age are associated with burnout (Marchand et al., 2015). For instance, associations examined by gender reported that women had a higher level of burnout than men, and the difference seems to be greater in emotional exhaustion than in depersonalization (Purvanova, Muros, 2010). Gender could be expected to moderate the relationship between burnout 
syndrome and age since women and men are exposed to nonwork and work stressors (Theorell et al., 2014). For example, men are more often exposed to better work conditions and less to work-family conflicts (Byron, 2005). Gender plays a meaningful function in the way in which work is experienced, rewarded, organized, not only in terms of work-related segregation, inequality in earnings, mobility, work status, but also in work behavior, social relations, and attitudes (Wharton, 2013). A cross-sectional study carried out among Spanish university professors analyzed gender differences in stress and burnout-related factors and showed up that female professors reported a higher burnout perceived by emotional exhaustion, neuroticism, and stress than males (Redondo-Flórez et al., 2020).

Leaders or managers may transfer positive emotions to followers via the tone of positivity in the workplace, which improves cooperation and decreases conflicts. Also, their followers in the positive leadership condition generate more original and valuable problem solutions (Morganson et al., 2014). Appropriate leadership should be used to encourage work-family balance and well-being not only among employees since managers are perceived as a significant source of worklife balance support (Todd, Binns, 2013). A manager has to cope with depressed, suspicious, the least proficient of the employees, the rivalrous, the self-centered, and generally unhappy subordinates. The manager has to balance mentioned incompatible personalities and create a motivating work unit. Managing people is the most challenging administrative charge, and it has built-in frustration. which causes managers to burn out (Levinson, 1996). A cross-sectional study conducted among 4737 managers from Sweden investigated gender disparities in attitudes of first-line managers to employees with depression. From the perspective of gender and attitudes of managers towards depressed employees, female managers reported a lower degree of negative attitudes than men. It is important to study gender differences in attitudes towards depression, due to the global and increasing trend in the number of female managers (Mangerini et al., 2020). It was conducted a study with the aim to see what factors lead to a higher level of burnout among entrepreneurs. It observed whether job passion, destiny beliefs (the belief that a successful carrier is 'meant to be'), and job fit make entrepreneurs less likely or more likely to experience burnout syndrome. The study showed that the majority of entrepreneurs (4.26 on a five-point scale) reported a high level of job fit, $25 \%$ of entrepreneurs felt relatively burned out, while $3 \%$ felt strongly burned out. The individuals who reported a high score of obsessive passion (2.58) were more prone to say that they experienced burnout than those who reported a high score of harmonious passion (3.90). The obsessively passionate individuals described that work was emotionally draining and it required greater effort (Mol et al., 2018). Considering previous findings, we can understand the seriousness of the association between challenging demands of managerial work and the resulting stress, often causing mental exhaustion.

\section{Theoretical background of Coping in terms of gender among managers}

According to the requirements of a situation, a coping strategy is changing for the individual over some time, and using strategies is considered as disposition trait or addictive preference for approaching difficulty, or authentic effort applied in different situations (Day, Livingstone, 2003). Problem-focused strategies are active coping, planning, seeking social support for the instrumental reason (assistance or seeking advice), testing other activities, suppression of competitive activities, restraint coping (forcing oneself to wait before acting), and confrontational coping, reflecting on experience (Dunkley, 2018). Individuals use more often problem-focused coping strategies when the situation is appraised as controllable and/or changeable or when individuals feel that something constructive can be done (Carver et al., 1989). Emotion-focused coping strategies seek out social support for emotional reasons (getting moral support, understanding, and sympathy), avoidant or escape coping (wishful thinking), reduction of tension (try to make feel better by eating, smoking, drinking, drugs, or medications), distraction or denial (refusing to believe that the problem is real), distancing, self-isolation, behavioral disengagement, acceptance (learning to accept the problem), positive reappraisal, self-blame, accepting responsibility, rumination (repeatedly worrying about the problem), turning to religion (using faith for support), humor, etc. (Carver et al., 1989; Dyson, Renk, 2006; Folkman, Lazarus, 1985; Folkman et al., 1986; Li et al., 2006; Litman, 2006; Wong et al., 2017). These coping strategies are predominantly used by individuals who feel the stressor as something that must be endured and when the situation is appraised as unchangeable (Howerton, Van Gundy, 2009). The literature on coping may provide an underpinning for managers seeking to practice work-family self-care. Preventive coping strategies which involve taking action before a conflict occurs are ideal (Major, Lauzun, and Jones, 2013). By engaging in self-care strategies and modeling the effective work-family management, managers can enable work-family balance of subordinates (Morganson et al., 2014). There are nine evidencebased strategies and challenges for organizations and their managers: acknowledge and assess the problem, harness the power of effective leadership, develop and implement targeted interventions, cultivate community at work, use rewards and incentives wisely, align values and strengthen culture, promote flexibility and work-life integration, provide resources to promote resilience and self-care, facilitate and fund organizational science. The overall success of an organization and its managers cannot be achieved only by implementation a particular business strategy - it should be supported by human resources (Susanto, 2016). Appropriate strategies should encourage engagement and reduce manifestations of burnout syndrome from occupation. Some concepts are expensive but demonstrate a significant impact (Shanafelt, Noseworthy, 2017). A study about certain coping strategies and the perception of employees of organizational work-life balance programs indicated that individuals with positive life coping strategies and attitudes were more efficient in achieving overall well-being (Zheng et al., 2016). In other words, coping can refer to thoughts and acts that managers use to accomplish a stressful situation as well as emotions. This matter does not concern only managers, but also individuals who have to work on their own responsibility. Even we know about the relationship between the experience of positive emotions and self-employment such as passion, satisfaction, happiness, there exist studies which suggest that the self-employed are more vulnerable to negative emotions such as stress, fear of failure, mental strain, grief or Ioneliness (Patzelt, Shepherd, 2011).

Two factors bond managerial development and work stress - the role of the environment and the role of the person. To manage strain and to cope with work-related stressors, managers must be able to differentiate between factors in the environment that are potential sources of stressors and how individuals perceive those factors. When the process of coping is not successful, some strain may appear (Glazer, Liu, 2017). It has been found out that senior and junior managers working in an information technology company experienced a similar level of work-related stress even if it was significantly different. Work satisfaction and mental well-being were correlated but no significant. Work contentment was significantly correlated with coping behavior. It could be explained that if mental health and 


\section{GENERAL MANAGEMENT}

work satisfaction increase, coping behavior increases. And if stress increases, mental well-being decreases (Rao, Chandraiah, 2012).

Similar research was conducted, and the results reported that women scored significantly higher than men in the emotional and avoidance coping styles and lower in rational and detachment coping. Men were found to have more emotional restraint than women. Women were more likely to use avoidance coping strategies than men (Matud, 2004). The longitudinal study displayed that females were more likely than men to pursue social support and their coping strategies were more strongly influenced by emotional and social background and interpersonal association (Krajewski, Goffin, 2005). But men were principally socialized to practice problem-focused strategies (Liang et al., 2007) and to develop acting skills, planning, competing activities (Burke, 2002). Differences in terms of gender are perceived in a wide range of disorders connected with stress e.g., women employees are more likely to become depressive, which leads to a higher degree of sick leaves, disabilities, or retirements at an early age. But different studies stated that women use both coping styles more than men (McMahon et al., 2013). Overall, males use more problemfocused coping styles, however, women use more emotionfocused coping styles and tend to seek often social support. Women tend to use more maladaptive emotion-focused coping strategies, such as seeking help, rumination, crying, etc. (Howerton, Van Gundy, 2009; Ros et al., 2014). The study about the relationship between stress, gender, and quality of social support reported that gender, quality of social support, and age significantly predicted perceived stress and that there exists an interaction between quality of social support and gender (Kneavel, 2020). Women use social support networks as a resource to create awareness about emotional distress - need to talk about it, and men use social support networks to normalize and control their emotional distress - to forget about it by going out, partying, having fun, etc. (Martínez-Hernáez et al., 2016).

\section{The Study}

The research examines whether there exist positive gender differences in three attributes of burnout syndrome: Emotional Exhaustion, Depersonalization, and Personal Accomplishment in managers, and whether there exist positive gender differences in fourteen coping strategies in managers. The presumed hypothesis was that there exist positive differences between the assessment of individual determinants of burnout syndrome in managers and the assessment of selected coping strategies used in difficult situations in terms of gender. The main objective of this quantitative study was to find out whether certain coping strategies prevent burnout by a selection of the appropriate coping strategy, to enrich the field of information linked to psychological concerns related to managers in terms of burnout, and to describe differences in men and women in terms of coping strategies and burnout. The criterion for evaluating the effectiveness of a certain strategy is its contribution to the moderation of impacts of burden or its complete elimination while maintaining the work position of the disturbed individual (Vitková, Zábrodská, 2014).

\section{The Sample}

The research sample involved 249 respondents aged from 23 to 60 years $(M=40.28, S D=8.82)$, of which 134 were men
(54\%) and 115 were women (46\%). The data were collected by online questionary with the ambition to obtain a representative sample of top management ( $\mathrm{N}=72 ; 29 \%)$, middle management $(\mathrm{N}=86 ; 34 \%)$, and first-level management $(\mathrm{N}=91 ; 37 \%)$. The maximum length of managerial practice was 35 years $(M=9.43$, $\mathrm{SD}=7.6)$. The answers were analyzed by using a t-test for two independent selections in the statistical software program SPSS 22.

\section{Methodology}

The research was managed through the methodology of the Maslach Burnout Inventory that serves to measure the degree of burnout syndrome and it is composed of twenty-two questions, separately dealing with three determinants. A determinant of Personal Accomplishment (PA) is evaluated as positive, Emotional Exhaustion (EE) and Depersonalization (DP) are evaluated as negative (Maslach, Jackson, and Leiter, 1996). If respondents obtain EE values of 27 and higher, or DP values of 10 and higher, they experience at least one symptom of burnout. Respondents had the opportunity to choose on the Likert scale from the frequency rating options: $0-$ never, $1-$ several times per year, 2 - monthly, 3 - several times per month, 4 - weekly, 5 - several times per week, 6 - daily. We perceive burnout syndrome as a continuum and believe that the MBI methodology determines its level properly. Besides, it indicates the appropriateness of utilizing the methodology to detect signals of burnout in managers. The research was also managed through the Brief COPE Inventory. Previously, it was designed by its author as the original The Full COPE Inventory, but due to its complexity, it was shortened to the present version with a lower number of items (Carver, Scheier and Weintraub, 1989). It was used to find out how managers act to deal with the burden and what coping strategies they frequently choose in challenging situations. It delineates fourteen approaches (strategies) about how to cope with the demanding situation, and every approach is divided into two questions. The Brief COPE Inventory involves 28 questions with a four-point scale with the following answers: 0 - I have not been doing this at all, $1-1$ have been doing this sometimes, 2 - I have been doing this often, 3 - I have been doing this a lot. Managers were asked how often they choose a certain coping strategy to deal with a stressful situation and which coping strategies are the most typical for them. Our attention was dedicated to assessing fourteen coping strategies in managers in terms of gender.

\section{Results}

We assumed the existence of positive and significant differences in attributes of burnout syndrome (Table 1) and coping strategies (Table 2). The assessment of the answers of managers by using a t-test for independent samples showed that there exist statistically significant differences $(p<.001)$ in women and men in two determinants of burnout syndrome and in six coping strategies in terms of challenging situations. Male managers reported higher levels of Emotional Exhaustion and Depersonalization in comparison to female managers (Table 1). Managers in terms of gender used the Approach and the Avoidance coping strategies (planning, denial, social support, venting, self-blame) (Table 2). Religion and Humor are neither Approach nor Avoidance coping strategies. 


\section{GENERAL MANAGEMENT}

\begin{tabular}{|c|c|c|c|c|c|c|c|c|}
\hline Determinants & Gender & $\mathbf{N}$ & $\mathbf{M}$ & SD & t-test & Sig. & $\begin{array}{l}\text { Mean } \\
\text { difference }\end{array}$ & $\begin{array}{l}\text { SE } \\
\text { difference }\end{array}$ \\
\hline Emotional & women & $\frac{115}{134}$ & $\begin{array}{l}2.103 \\
2.468\end{array}$ & $\begin{array}{l}0.661 \\
0.857\end{array}$ & -2.894 & $0.006^{* *}$ & -0.264 & 0.098 \\
\hline \multirow[b]{2}{*}{ Depersonalization } & $\begin{array}{l}\text { men } \\
\text { women }\end{array}$ & $\frac{134}{115}$ & $\frac{2.468}{2.344}$ & $\begin{array}{l}0.857 \\
0.631\end{array}$ & \multirow[b]{2}{*}{-2.635} & \multirow[b]{2}{*}{$0.023^{*}$} & \multirow[b]{2}{*}{-0.195} & \multirow[b]{2}{*}{0.068} \\
\hline & $\begin{array}{l}\text { women } \\
\text { men }\end{array}$ & $\frac{115}{134}$ & $\begin{array}{l}2.344 \\
2.840\end{array}$ & $\begin{array}{l}0.631 \\
0.745 \\
\end{array}$ & & & & \\
\hline $\begin{array}{l}\text { Personal } \\
\text { Accomplishment }\end{array}$ & $\begin{array}{l}\text { women } \\
\text { men }\end{array}$ & $\begin{array}{l}115 \\
134\end{array}$ & $\begin{array}{l}2.944 \\
2.838 \\
\end{array}$ & $\begin{array}{l}0.578 \\
0.618 \\
\end{array}$ & 1.389 & 0.166 & 0.105 & 0.076 \\
\hline
\end{tabular}

${ }^{* *} p<.001,{ }^{*} p<.05$

Table 1: Student's t-test for independent samples between determinants of burnout in male and female managers

The results showed that there are significant differences in a determinant of Emotional Exhaustion $\mathrm{t}(244)=-2.747, \mathrm{p}=0.006$ in terms of gender. The average score of men $(M=2.468, S D=$ $0.857)$ was significantly different from the average score of women $(M=2.103, S D=0.661)$. Managers reported a higher level of Emotional Exhaustion because they felt workload and exhaustion after every thought of the job, they experienced the loss of motivation what could lead to depression, anxiety, or frustration, and they lacked the strength to accomplish any activity.

The results indicated that there exist significant differences in determinant of Depersonalization $\mathrm{t}(247)=-2.635, \mathrm{p}=0.023$. The average score of men $(M=2.840, S D=0.745)$ was significantly different from the average score of women $(\mathrm{M}=$
2.344, $\mathrm{SD}=0.613$ ). This dissociative disorder occurred as insensitivity in a wide range of conditions where managers experienced unpleasant feelings of detachment from reality, often due to sleep loss, venting emotions that often went with anger or blaming, lessened collegiality, substance addiction, or unclear organizational goals. Based on dissociated thoughts they often did not feel being themselves.

Any statistically significant gender differences were not reported in a determinant of Personal Accomplishment. To interpret the results, it would be necessary to look at the insignificant

of differences between women and men.

Analysis of answers indicated (Table 2) statistically significant gender differences $(p<.001)$ in coping strategies in terms of difficult situations by using a t-test for two independent selections.

\begin{tabular}{|c|c|c|c|c|c|c|c|c|}
\hline Strategies & Gender & $\mathbf{N}$ & M & SD & t-test & Sig. & $\begin{array}{l}\text { Mean } \\
\text { difference }\end{array}$ & $\begin{array}{l}\text { SE } \\
\text { difference }\end{array}$ \\
\hline \multirow{2}{*}{ Self-distraction } & women & 115 & 1.200 & 0.580 & \multirow{2}{*}{1.104} & \multirow{2}{*}{0.271} & \multirow{2}{*}{0.080} & \multirow{2}{*}{0.079} \\
\hline & men & 134 & 1.111 & 0.665 & & & & \\
\hline \multirow{2}{*}{ Active coping } & women & 115 & 1.834 & 0.511 & \multirow{2}{*}{-0.842} & \multirow{2}{*}{0.400} & \multirow{2}{*}{-0.057} & \multirow{2}{*}{0.067} \\
\hline & men & 134 & 1.891 & 0.549 & & & & \\
\hline \multirow{2}{*}{ Denial } & women & 115 & 1.565 & 0.417 & \multirow{2}{*}{-3.775} & \multirow{2}{*}{$0.000^{* *}$} & \multirow{2}{*}{-0.281} & \multirow{2}{*}{0.074} \\
\hline & men & 134 & 1.977 & 0.701 & & & & \\
\hline \multirow{2}{*}{ Substance abuse } & women & 115 & 0.252 & 0.399 & \multirow{2}{*}{-1.580} & \multirow{2}{*}{0.115} & \multirow{2}{*}{-0.102} & \multirow{2}{*}{0.064} \\
\hline & men & 134 & 0.354 & 0.587 & & & & \\
\hline \multirow{2}{*}{ Social support } & women & 115 & 2.556 & 0.609 & \multirow{2}{*}{2.267} & \multirow{2}{*}{$0.031^{*}$} & \multirow{2}{*}{0.082} & \multirow{2}{*}{0.080} \\
\hline & men & 134 & 1.738 & 0.652 & & & & \\
\hline \multirow{2}{*}{ Instrumental support } & women & 115 & 1.434 & 0.744 & \multirow{2}{*}{-0.633} & \multirow{2}{*}{0.527} & \multirow{2}{*}{-0.057} & \multirow{2}{*}{0.091} \\
\hline & men & 134 & 1.492 & 0.693 & & & & \\
\hline \multirow{2}{*}{$\begin{array}{l}\text { Behavioral } \\
\text { disengagement }\end{array}$} & women & 115 & 0.673 & 0.508 & 1181 & 0.110 & $010 ?$ & 0060 \\
\hline & men & 134 & 0.776 & 0.570 & -1.481 & 0.140 & -0.102 & 0.069 \\
\hline Venting & women & 115 & 1.321 & 0.518 & -3559 & 0000 ** & -0271 & 0078 \\
\hline Ventıng & men & 134 & 1.932 & 0.691 & -3.559 & $0.000^{* x}$ & -0.271 & 0.078 \\
\hline Positive reframing & women & 115 & 1.904 & 0.658 & 1.576 & 0.116 & 0.146 & 0.093 \\
\hline & $\begin{array}{l}\text { men } \\
\text { women }\end{array}$ & $\frac{134}{115}$ & $\begin{array}{l}1.757 \\
1.973\end{array}$ & $\begin{array}{l}0.791 \\
0.760\end{array}$ & $1.5 / 0$ & & & \\
\hline Planning & men & 134 & 2.835 & 0.650 & -3.464 & $0.001^{\star *}$ & -0.309 & 0.089 \\
\hline & women & 115 & 2.121 & 0.742 & & & & \\
\hline Humor & men & 134 & 1.839 & 0.812 & 2.863 & $0.005^{\star \star}$ & 0.282 & 0.099 \\
\hline Accentance & women & 115 & 1.704 & 0.521 & 0.441 & 0659 & 0032 & 0074 \\
\hline Acceptance & men & 134 & 1.671 & 0.631 & 0.441 & 0.659 & 0.032 & 0.074 \\
\hline Snirituality & women & 115 & 1.487 & 0.857 & 0792 & 0.429 & 0110 & 0139 \\
\hline & men & 134 & 1.376 & 1.261 & 0.792 & 0.429 & & \\
\hline colk hlom & women & 115 & 1.873 & 0.557 & Pcre & קח & 0100 & (2000 \\
\hline Self-blame & men & 134 & 1.235 & 0.729 & 2.662 & $0.020^{*}$ & 0.182 & 0.083 \\
\hline
\end{tabular}

${ }^{* *} p<.001,{ }^{*} p<.05$

Table 2: Student's t-test for independent samples between coping strategies used by male and female managers 
In the coping strategy of Denial $\mathrm{t}(221)=-3.916, \mathrm{p}=0.000$, the average score of men $(M=1.977, S D=0.701)$ was significantly different than the score of women $(\mathrm{M}=1.565, \mathrm{SD}=$ 0.417), since male managers used the avoidance strategy as a defensive response of suppressing, frustration and their fantasies. Managers who achieved a higher score refused to believe that something unpleasant happened and exist and had a tendency to behave like stressors did not exist - hence at the first evaluation of the situation, subjectively reduced the perception of the severity of the situation and saved energy for further stressful situations. Managers did not have a tendency to admit that what was happening was for real, and they kept thinking that what happened was simply not real.

In the coping strategy of Social support $t(247)=2.267, p=$ 0.031 , the average score of women $(M=2.556, S D=0.609)$ was significantly different than the average score of men $(M=1.738$, SD = 0.652), since female managers used as a defense mechanism the effort to gain understanding and sympathy by seeking psychological and emotional support from acquaintances and close friends, to whom they could reveal emotions to received feedback. Emotional and social support presented for them an understanding and reassurance to express worries since they wanted to get out of stressful situations as better and more experienced individuals. As instrumental social support, they used a piece of advice of experts, or assistance at work with the aim not to give up and fight.

In the coping strategy of Venting $\mathrm{t}(243)=-3.535, \mathrm{p}=0.000$, the average score of men $(M=1.933, S D=0.691)$ was significantly different than the average score of women $(\mathrm{M}=$ $1.321, \mathrm{SD}=0.518$ ), therefore male managers used to focus on their feelings and the effort to express them as a coping strategy of emotional relax, what in this case was a manifestation of grumpiness, irritability, anger, disappointment, blame, etc. So, it was ventilation or emotional relaxation, which they used as a psychological vent that allowed them to focus on other situations. It is needed to emphasize that this strategy can be an obstacle to constructive solutions when it is used at the wrong timing.

In the coping strategy of Planning $t(226)=-3.423, p=0.001$, the average score of men $(M=2.836, S D=0.650)$ was significantly different than the average score of women $(\mathrm{M}=$ $1.974, \mathrm{SD}=0.760)$, since male managers recognized their priorities and did not waste energy uselessly. Managers used frequent planning and organization of activities as the effective coping strategy, while considering breaks between individual activities, they had the goal to clarify the procedures of solutions. They had a tendency to think of other ways to manage the burden more easily and reduce stressors. With this active way of managing stressful situations, managers tried to avoid pressure from another and unexpected stressors. They experienced effective planning of future activities as often as possible.

In the coping strategy of Humor $\mathrm{t}(247)=2.863, \mathrm{p}=0.005$, the average score of women $(\mathrm{M}=2.122, \mathrm{SD}=0.742)$ was significantly different than the average score of men $(\mathrm{M}=1.839$, $\mathrm{SD}=0.813$ ), since female managers appreciated the cheerful and entertaining company and as a coping strategy they sought entertainment that was considered as a temporary escape from encumbrance. Female managers considered it as work enrichment, an effective way to diversify monotonous professions. Again, it is worth emphasizing that humor as a strategy can be the manifestation of either looking at a given situation or denying the seriousness of the situation in which individuals find themselves.

In the coping strategy of Self-blame $t(244)=2.231, p=$ 0.027 , the average score of women $(M=1.874, S D=0.558)$ was significantly different than the average score of men $(M=1.235$,
$\mathrm{SD}=0.729$ ), since female managers used an avoidance coping strategy while they blamed themselves for things that happened, they were too critical of themselves, felt a lack of inner selfconfidence, felt irrational anger whenever they were unsuccessful, unheard of, or unteachable of making same mistakes. Female managers blamed themselves even for not trying to escape this destructive cycle, subconsciously punished themselves, and faced negative inner voices. It is practical to point out the seriousness of such thinking since it is suitable to change a negative internal dialogue and re-establish the overall thinking of the affected individual.

Coping strategies of religiosity, acceptance, positive transformation, substance abuse, behavioral disengagement, active coping, instrumentational support, and self-distraction were the least used strategies in the representative sample, and no statistically significant differences were reported.

The paper highlighted the seriousness of the matter since we are aware that it causes psychosomatic difficulties in the mental and physical state of individuals. Fortunately, the outcomes revealed that male and female managers use various effective coping strategies to handle the burden. We aimed to emphasize the burnout syndrome phenomenon in the field of management since it is appropriate to be indifferent from other occupations and focus on occupations that are also prone to experience burnout syndrome, e.g., managers, teachers, students, artists, athletes, entrepreneurs, lawyers, etc.

\section{Discussion}

The results reported statistically significant differences between determinants of burnout syndrome and coping strategies in terms of gender in a representative sample of managers. The use of certain coping strategies could be based on excessive occupational demands often caused by development and expansion of knowledge in fields of management, or technological and scientific progress, or even by domestic demands. According to Voitenko et al. (2021), a predictor of positive adaptation to requirements of occupational needs is a feature of personal coping manners that should have a moderating effect on strain issues. In the case of the representative sample of managers, strategies of Humor, Planning, Social support, Venting could be considered as strategies with moderating effect, since we consider these strategies as effective ways in fighting daily work demands, often connected with family responsibilities. We suppose that these strategies played the important role in the struggle with Emotional Exhaustion that could have the mediating problem in work-family conflicts, and a representative sample of managers found them prosperous in difficult times.

In connection with the occurrence of burnout syndrome, women are perceived as a higher risk group in comparison to men. A frequent reason is a higher burden caused by job responsibilities, associated with household management or upbringing of children (Morovicsová, Krajčovičová, and Kostovičková, 2017). A study about personality and individual differences stated that females reported life events as less manageable and more negative in comparison to males, women listed health-related and family events more frequently whilst the men listed finance, relationship, and work-related events (Matud, 2004). According to Adekola (2009), female workforce in university experienced a lower statistically significant level of Personal Accomplishment in comparison to male counterparts. In the case of managers, even when female managers reported a higher level of Personal Accomplishment $(\mathrm{M}=2.945, \mathrm{SD}=$ $0.578)$ in comparison to men $(M=2.839$, $S D=0.618)$, these findings were not statistically significant. Based on the literature studied so far, the burnout phenomenon is seen as gender- 
neutral but leaves a gap in the literature in significant differences in experiences of burnout in men and women and their coping manners.

The assessment of both genders showed that there were significant differences between men and women in the field of management. Comparable results were displayed in the study by Gazdíková (2017) where men were more prone to burnout in comparison to women. For instance, a study evaluated the intensity of burnout and depression in 7428 Czech doctors $(46 \%$ of women, $54 \%$ of men of productive ages between 25 and 60 years). Symptoms of burnout were identified in up to $34 \%$ of physicians which could be assessed as very serious, and only $8 \%$ of doctors of the whole sample (10\% of general practitioners) stated that they never or very rarely experienced symptoms of burnout. In contrast, $10 \%$ of physicians described moderate or severe symptoms of depressions. It was disturbing to find that up to $1 / 3$ of the evaluated sample was created by burned-out doctors. The occurrence was significantly higher in male physicians compared to women doctors, which is probably conditioned by the ability of women to admit burnout syndrome and start to deal with it.

We assume that in the case of the sample of managers, statistically significant difference appeared in Emotional Exhaustion in men $(\mathrm{M}=2.468, \mathrm{SD}=0.857)$ because they were unwilling to admit the possibility of failure, did not seek social support, professional or amateur help, manifested non-engaged behavior and did not stop thinking about the problem, had a tendency to procrastinate, and regularly gave up in achieving desired goals. But female managers $(M=2.103, S D=0.661)$ managed to avoid Emotional Exhaustion by effectively dealing with it in terms of suitable coping strategies. A study about practices of project managers dealing with a burden stated that male managers often apply strategies of Planning and Active coping, and two statistically significant correlations between gender and coping strategies were revealed when women were more prone to use Social and Instrumental support (Aitken \& Crawford, 2007). Comparably to the case of the sample of managers, female managers applied coping strategies of Humor, Social support, and Self-blame, the values of which were statistically significant. We assume that a strategy of Humor, helped them to build resilience to stress as well as improve overall emotional and physical health, it empowered them to create healthy bonds with others, normalize experiences, kept relationships strong, and perceive things differently. We consider it as a modern way of modifying workload. In the case of Self-blame, female managers reported the experienced consequences thar were a direct result of their actions or even character. Garnefski and Kraaij (2014) add that managers who use Active coping strategies in association with positive reconsideration are more resilient people than those who use strategies as Self-blame. In terms of behavioral medicine, it could be either beneficial or harmful. It depends if it leads to positive behavior change or increased lack of change of behavior. We agree with Salazar et al.'s (2014) idea who stated that the significance of including coaching of assertiveness as another coping strategy could help to overcome any burden since they reported it associated with a lack of personal accomplishment, exhaustion, and social anxiety.

Managers who are in the process of burning out would have support from others who offer suitable psychological support (Levinson, 1996). Those others could preferably be supervisors who value them as individuals, and in times of strain, managers should keep up a personal interaction with the surrounding. According to the statement, we assume that sympathy is the source of decent care, not only medical. It helps to recognize sorrow, all the solicitudes, distresses, and it takes steps to moderate it. Hofmeyer, Taylor, and Kennedy (2020) stated that the main and the right tools are listening, empathy, respect, interpersonal skills, and at least understanding of an individual's state and conditions. Also, organizational communication can be reflected as an essential factor in the well-being of individuals since it is connected with the performance and competencies of managers (Susanto, Titisari, and Parwitasari, 2021). Managers should be encouraged to cooperate with their surroundings and provide accurate information (Verulava, Bedianashvili, 2021). We are aware that in the long run, this factor has a positive influence on the quality of job performance.

\section{Conclusion}

Findings that there exist statistically significant differences in male managers in determinants of Emotional Exhaustion and Depersonalization, and that there do not exist statistically significant differences in Personal Accomplishment, are important since it calls for the attention of experts. The research will hopefully help to raise awareness about professional health of individuals who are prone to experience burnout syndrome. Chronic stress is nothing unusual and our minds could pay a high price. As it was reported, at some level of burnout, managers had reduced subjective accomplishment, lacked personal contribution with others, had a low perception of capability, had feelings of being disconnected from the surrounding. Not only individuals working as managers should learn to recognize manifestations of burnout, and not only people working as managers should require organizational or instrumental support to deal with burden. Everyone should be able to take preventive steps at the early beginning of any symptoms. In conclusion to this matter, we summarize few facts that we realized while studying this topic, and we consider it as spontaneous due to a certain stage of the syndrome - chronic burnout strengthens self-undermining and the cycle of loss of daily work demands, burnout undermines the cycle of gaining daily job resources and work crafting, and individuals with a higher level of burnout syndrome should have tailor-made help. Burnout can affect anyone of us and what is more, certain differences are noticeable in its occurrence, especially in gender, personality traits, and behavior of managers. Work passion, job fit, mindset, and burnout are inseparably linked understanding that passion is a double-edged sword may help managers to observe motivations or work behavior to prevent their careers from burnout. For instance, without good time management, managers will persistently feel rushed, stressed, or risking unreasonable decisions. There exist things the manager can control - his or her thoughts, behavior, and vicinity. Similarly, the key is being professional but human, open, friendly, honest but caring personal things, hardworking but realistic, helpful but not paternalistic (Stringer et al., 2015). We chose to focus on gender since it is confounded with factors such as occupation, social roles, educational background, expectations, and according to Maslach, Leiter (2008) even with political or economic realities. Although burnout syndrome presents a system question, many experiences demonstrate that considered, sustained, and comprehensive efforts to decrease burnout and promote engagement can make a great difference.

\section{Limitations}

Like any other research we referred to in the paper, the study has certain limitations, resulting from self-selection and selfexpression. Possibly, individuals with the worst burnout symptoms did not participate in the research. However, the findings, which point to a serious situation in connection with burnout, do not give the impression that the answers of respondents were embellished or otherwise adapted. According 
to the current overview of the issue, we may say that an important role can be played not only by the characteristics and the resulting differences at the level of individuals but also due to cultural and national differences, or in family habits in the upbringing. For example, the specificity of the position of women in society, different working conditions, the legal framework for the performance of the managerial profession, etc. These could explain inconsistent findings of the role of gender in the incidence and intensity of burnout symptoms in managers. We also propose the implementation of meta-analyzes that provide reliable conclusions than the individual studies.

\section{Acknowledgement}

This article was supported by the scientific grant project GaPU 30/2020 - Grant Agency for Doctoral Students and Young Researchers of the University of Prešov in Prešov. This paper was supported by project 012PU-4/2020 KEGA: Trading Behavior - Creation of the subject and textbook for noneconomic study programs.

\section{References}

[1] Adekola, B. (2009). Gender differences in the experience of work burnout among university staff. African Journal of Business Management, 4(6), pp. 886-889.

[2] Aitken, A., \& Crawford, L. (2007). Coping with stress: Dispositional coping strategies of project managers. International Journal of Project Management, 25(7), 666-673. doi:10.1016/j.ijproman.2007.02.003

[3] Bakker, A. B., \& Costa, P. L. (2014). Chronic job burnout and daily functioning: A theoretical analysis. Burnout Research, 1(3), 112-119. doi:10.1016/j.burn.2014.04.003

[4] Brubaker, J. R., \& Beverly, E. A. (2020). Burnout, Perceived Stress, Sleep Quality, and Smartphone Use: A Survey of Osteopathic Medical Students. Journal of Osteopathic Medicine, 120(1), 6-17. doi:10.7556/jaoa.2020.004

[5] Burke, R. J. (2002). Men, masculinity, and health. In: Gender, work stress, and health. Washington: American Psychological Association, pp. 35-54.

[6] Byron, K. (2005). A meta-analytic review of work-family conflict and its antecedents. Journal of Vocational Behavior, 67(2), 169-198. doi:10.1016/j.jvb.2004.08.009

[7] Carter, S. B. (2013). The tell-tale signs of burnout. Do you have them? Psychology Today. Available at: https://www.psychologytoday.com/int//blog/high-octanewomen/201311/the-tell-tale-signs-burnout-do-you-have-them

[8] Carver, C. S., Scheier, M. F., \& Weintraub, J. K. (1989). Assessing coping strategies: A theoretically based approach. Journal of personality and social psychology, 56(2), pp. 267-283.

[9] Day, A. L., \& Livingstone, H. A. (2003). Gender differences in perceptions of stressors and utilization of social support among university students. Canadian Journal of Behavioural Science/Revue Canadienne Des Sciences Du Comportement, 35(2), 73-83. doi:10.1037/h0087190

[10] Dunkley, D. M. (2018). Perfectionism and daily stress, coping, and affect: Advancing multilevel explanatory conceptualizations. In J. Stoeber (Ed.), The psychology of perfectionism: Theory, research, applications. Routledge/Taylor \& Francis Group, pp. 222-242.

[11] Dyson, R., \& Renk, K. (2006). Freshmen adaptation to university life: depressive symptoms, stress, and coping. Journal of Clinical Psychology, 62(10), pp. 1231-1244.

[12] Folkman, S., \& Lazarus, R. S. (1985). If it changes it must be a process: Study of emotion and coping during three stages of a college examination. Journal of Personality and Social
Psychology, 48(1), 150-170. doi:10.1037/0022-3514.48.1.150

[13] Folkman, S., Lazarus, R. S., Dunkel-Schetter, C., DeLongis, A., \& Gruen, R. J. (1986). Dynamics of a stressful encounter: Cognitive appraisal, coping, and encounter outcomes. Journal of Personality and Social Psychology, 50(5), 992-1003. doi:10.1037/0022-3514.50.5.992

[14] Gazdíková, K. (2017). Burnout syndrome in healthcare professionals. Via pp. $178-185$.

[15] Glazer, S., \& Liu, C. (2017). Work, Stress, Coping, and Stress Management. In Oxford Research Encyclopedia of Psychology. Oxford University Press. Available at: https://doi.org/10.1093/acrefore/9780190236557.013.30

[16] Garnefski, N., \& Kraaij, V. (2014). Bully victimization and emotional problems in adolescents: Moderation by specific cognitive coping strategies? Journal of Adolescence, 37(7), 1153-1160. doi:10.1016/j.adolescence.2014.07.005

[17] Heinemann, L. V., \& Heinemann, T. (2017). Burnout research: Emergence and scientific investigation of a contested diagnosis. SAGE Open, 7(1), pp. 1-12.

[18] Hofmeyer, A., Taylor, R., \& Kennedy, K. (2020). Fostering compassion and reducing burnout: How can health system leaders respond in the Covid-19 pandemic and beyond? Nurse Education Today, 94, pp. 104502.

[19] Howerton, A., \& Van Gundy, K. (2009). Sex differences in coping styles and implications for depressed mood. International Journal of Stress Management, 16(4), 333-350.

[20] Kneavel, M. (2020). Relationship between gender, stress, and quality of social support. Psychological Reports. 0(0), pp. 1-21.

[21] Krajewski, H. T. \& Goffin, R. D. (2005). Predicting occupational coping responses: the interactive effect of gender and work stressor context. Journal of occupational health psychology, 10(1), pp. 44-53.

[22] Levinson, H. (1996). When executives burn out. Harvard Business Review. Available at: https://hbr.org/1996/07/whenexecutives-burn-out

[23] Li, S., et al. (2006). The impact of supply chain management practices on competitive advantage and organizational performance. Omega. 34(2), pp. 107-124.

[24] Liang, C. T. H., et al. (2007). The role of coping in the relationship between perceived racism and racism-related stress for Asian Americans: Gender differences. Journal of Counseling Psychology, 54(2), pp. 132-141.

[25] Litman, J. A. (2006). The COPE inventory: Dimensionality and relationships with approach-and avoidance-motives and positive and negative traits. Personality and Individual Differences, 41(2), pp. 273-284.

[26] Major, D. A., Lauzun, H. M., \& Jones, M. P. (2013). New directions in work-family coping research. In: Expanding the Boundaries of Work-Family Research. London: Palgrave Macmillan UK, pp. 193-211.

[27] Mangerini, I., et al. (2020). Gender differences in managers' attitudes towards employees with depression: a cross-sectional study in Sweden. BMC Public Health, 20(1), pp. 1744.

[28] Marchand, A., et al. (2015). The multilevel determinants of workers' mental health: results from the SALVEO study. Social Psychiatry and Psychiatric Epidemiology, 50(3), pp. 445-459.

[29] Martínez-Hernáez, A., et al. (2016). Social support and gender differences in coping with depression among emerging adults: a mixed-methods study. Child and Adolescent Psychiatry and Mental Health, 10(2), pp. 1-11.

[30] Maslach, C., Jackson, S. E., \& Leiter, M. P. (1996). Maslach Burnout Inventory Manual (3rd ed.) (Vol. 3). Palo Alto, CA: Consulting Psychologists Press.

[31] Maslach, C. \& Leiter, M. P. (2008). Early predictors of job burnout and engagement. The Journal of applied psychology, 93(3), pp. 498-512.

[32] Matud, M. P. (2004). Gender differences in stress and coping styles. Personality and individual differences, 37(7), pp. 1401- 


\section{GENERAL MANAGEMENT}

1415.

[33] McMahon, E. M., et al. (2013). Mediating effects of coping style on associations between mental health factors and self-harm among adolescents. Crisis, 34(4), pp. 242-250.

[34] Mol, E., et al. (2018). What makes entrepreneurs burn out. Harvard Business Review. Available at: https://hbr.org/2018/04/what-makes-entrepreneurs-burn-out

[35] Morganson, V. J., et al. (2014). Promoting work-family balance through positive psychology: A practical review of the literature. The Psychologist Manager Journal, 17(4), pp. 221244.

[36] Morovicsová, E., Krajčovičová, D., \& Kostovičová., L. (2017). Occurrence of burnout syndrome in doctors at psychiatric clinics in Slovakia. Česká a Slovenská Psychiatrie, 113(5), pp. 203-210.

[37] Patzelt, H., \& Shepherd, D. A. (2011). Negative emotions of an entrepreneurial career: Self-employment and regulatory coping behaviors. Journal of Business Venturing, 26(2), pp. 226-238.

[38] Purvanova, R. K., \& Muros, J. P. (2010). Gender differences in burnout:

A meta-analysis. Journal of Vocational Behavior, 77(2), pp. 168-185.

[39] Rao, J. V., \& Chandraiah, K. (2012). Occupational stress, mental health and coping among information technology professionals. Indian Journal of Occupational and Environmental Medicine, 16(1), pp. 22-26.

[40] Redondo-Flórez, L., et al. (2020). Gender differences in stressand burnout-related factors of university professors. BioMed Research International, 2020(6), pp. 1-9.

[41] Ros, L., et al. (2014) "Overgeneral Autobiographical Memories: Gender Differences in Depression: Overgenerality, depression, and gender," Applied cognitive psychology, 28(4), pp. 472-480.

[42] Salazar, I. C., et al. (2014). Assertiveness and its relationship with emotional problems and burnout in healthcare professionals. Behavioral Psychology/ Psicología Conductual, 22(3), pp. 523-549.

[43] Shanafelt, T. D. \& Noseworthy, J. H. (2017). Executive leadership and physician well-being: Nine organizational strategies to promote engagement and reduce burnout. Mayo Clinic proceedings. Mayo Clinic, 92(1), pp. 129-146.

[44] Stringer, S. et al. (2015). Boundaries, time management and burnout. In Psychiatry: Breaking the ICE. Chichester, UK: John Wiley \& Sons, Ltd., pp. 25-30.

[45] Susanto, A. B. (2016). Model of Private Higher Education Competitive Advantage Strategy. Proceeding of 39th International Business Research Conference, 1(2), pp. 143155.
[46] Susanto, A. B., Titisari, P., \& Parwitasari, D. A. (2021). The Impact of Organization Communication and Competence on the Quality of Employees Performance through Organization Citizenship Behavior. Quality - Access to Success, 22(182), pp. 102-105.

[47] Swider, B. W., \& Zimmerman, R. D. (2010). Born to burnout: A meta-analytic path model of personality, job burnout, and work outcomes. Journal of Vocational Behavior, 76(3), pp. 487-506.

[48] Theorell, T., et al. (2014). Job strain and depressive symptoms in men and women: a prospective study of the working population in Sweden. Journal of Epidemiology and Community Health, 68(1), pp. 78-82.

[49] Todd, P., \& Binns, J. (2013). Work-life balance: Is it now a problem for management? Work-life balance: A problem for management? Gender, Work, and Organization, 20(3), pp. 219-231.

[50] Verulava, T., Bedianashvili, G. (2021). Work Inclusion of Persons with Disabilities: Employers' Perspectives. Quality Access to Success, 22(182), pp. 159-163.

[51] Vitková, M., \& Zábrodská, K. (2014). Coping and resistance to mobbing in the context of paradigmatic approach. Československá Psychologie, 58(3), pp. 254-269.

[52] Voitenko, E., et al. (2021). Influence of characteristics of selfactualization and coping behavior on resistance of teachers to professional stressors and emotional burnout. International Journal of Organizational Leadership, 10(1), pp. 1-14.

[53] Wharton, A. (2013). Gender and Work [Data set]. In Oxford Bibliographies Online Datasets. Oxford University Press (OUP). Available at: https://doi.org/10.1093/obo/9780199756384-0127

[54] World Health Organization (2019) Burn-out an "occupational phenomenon": International Classification of Diseases. Available at: https://www.who.int/news/item/28-05-2019-burnout-an-occupational-phenomenon-international-classificationof-diseases.

[55] Wong, Y. J., et al. (2017). Meta-analyses of the relationship between conformity to masculine norms and mental healthrelated outcomes. Journal of Counseling Psychology, 64(1), pp. 80-93.

[56] Zheng, C., et al. (2016). Impact of individual coping strategies and organisational work-life balance programmes on Australian employee well-being. The International Journal of Human Resource Management, 27(5), pp. 501-526. 